Note: This is a pre-publication final draft. For the published version, please see: Rafalow, Matthew H. (2018). "Disciplining play: digital youth culture as capital at school." American Journal of Sociology 123(5):1416-1452.

\title{
Disciplining Play: Digital Youth Culture as Capital at School ${ }^{1}$
}

\author{
Matthew H. Rafalow \\ Google
}

\begin{abstract}
Adults may still be catching up to digital age, but digital youth bring to school digital skills they learn from each other. Comparative ethnographic analysis of three middle schools that vary by student class and race reveals that students' similar digital skills are differently transformed by teachers into cultural capital for achievement. Teachers effectively discipline students' digital play, but in different ways. At a school serving working-class Latino youth, students are told their digital expressions are irrelevant to learning; at a school with mostly middleclass Asian-American youth, students' digital expressions are seen as threats to their ability to succeed academically; and at a private school with mainly wealthy White youth, students' digital skills are positioned as essential to school success. Insofar as digital competency represents a kind of cultural capital, the minority and working class students also have that capital. But theirs is not translated into teacher-supported opportunities for achievement.
\end{abstract}

Education scholars struggle with the fact that children arrive at school already shaped by their unequal childhoods. Young people from more privileged families develop cultural competencies from their parents that are similarly valued by teachers and administrators (Bourdieu and Passeron 1990; Lareau 2000; 2003). Ingrained knowledge and habits as subtle as knowing when and how to ask for a teacher's help net cumulative gains in schooling as early as elementary school (Calarco 2011). Researchers contend that to break from this pattern and create a more equal playing field there needs to be a redistribution of kids' cultural resources (DiMaggio 1982). This work suggests that if children had equal access to cultural competencies, educational inequalities would be minimized.

But childrearing may only be one element that informs social reproduction and inequality in education. Teachers may evaluate kids' very similar cultural competencies

${ }^{1}$ I thank Francesca Polletta, Cynthia Feliciano, Mizuko Ito, Ann Hironaka, Andrew Penner, Mark Warschauer, Mariam Ashtiani, Yader Lanuza, Edelina Burciaga, Jessica Kizer, participants at the University of California-Irvine Race Workshop, and anonymous reviewers for their feedback on previous iterations. This work was conducted under the auspices of University of California-Irvine and does not reflect the views or opinions of Google. Direct correspondences to 901 Cherry Avenue, San Bruno CA 94066. E-mail: mrafalow@google.com. 
quite differently depending on features of the school and their student demographic. To investigate this possibility, this study considers how teachers treat comparable digital skills that youth bring to school. I base these analyses on ethnographic data collected simultaneously in three technology-rich middle schools located in Southern California that vary by student race and class. At the time of data collection, youth from each school developed very similar digital skills not from their parents but from play with their peers. These similarities in kids' capacity to communicate online and produce digital media mirror national studies that show the profound generational similarities in digital uptake irrespective of race, class, and family origin (Hargittai 2003; Ito et al. 2009; Madden et al. 2013; NTIA 2000; Wellman et al. 2001; Zickhur 2010). The digital skills that youth develop through play online with friends could help them in school, particularly when federal and state education reforms increasingly cite digital skills as important for learning.

Despite similarities in digital skills acquired from play, I find that teachers differently value these competencies depending on the race and class of their student body. They discipline the day-to-day experiences of young people at school in distinct ways (Bowles and Gintis 1976; Foucault 1975; Freire 1996). Teachers' shared perceptions of students' needs, rooted in assumptions about the race and class of their student population, inform well-intentioned pedagogical approaches to kids' digital skills. Teachers enact these perceptions through the messages that they transmit to children about the value of their digital culture. At a school with mostly wealthy and White youth teachers communicate to children that skills from digital play represent valued capital for learning, whereas at schools with mostly minority and poor children students learn that their digital skills are threatening or irrelevant to their education. Social reproduction occurs because of schools' different disciplinary approaches to play, spurring ahead youth at privileged schools over others.

\section{CULTURAL REPRODUCTION AND MOBILITY PERSPECTIVES}

Research on cultural stratification in education argues that educators play an important role in determining whether the cultural skills youth bring to school matter for learning and achievement. This work suggests that family origin matters insofar as class-based childrearing strategies unequally prepare children for what is expected of them at school. More privileged families teach their children forms of knowledge that are valued by educational institutions, and less privileged families do not because they are not as connected to the dominant milieu. Bourdieu refers to this resource as cultural capital (Bourdieu 1977a; Bourdieu and Passeron 1990). Cultural capital reflects a familiarity with institutionalized signals that drive inclusion and exclusion, such as tastes for high culture or behaviors in line with shared expectations (Farkas 1996; Lareau and Horvat 1999; Swidler 1986). Indeed, studies find over and over that children arrive at school with different sets of habits and dispositions that are met unequally by teachers and systematically provide advantages to middle and upper class White children (Anyon 1980; 1981; Bowles and Gintis 1976; Calarco 2011; 2014a; 2014b; Carter 2005; Lareau 2000; 2003; McDonough 1997; Valenzuela 1999). Cultural reproduction theory would thus propose that teachers are a mechanism for social reproduction in that they selectively legitimate children's cultural resources. 
Scholars suggest that a redistribution of kids' cultural resources would break the cycle of social reproduction. DiMaggio (1982) first advocated this cultural mobility perspective when he found that working class children who possessed cultural capital, such as interests in high culture, achieved greater educational outcomes in high school. The value of these resources surpassed gains associated with parent education levels and former grades (DiMaggio and Mohr 1985). An extension of this argument is that teachers would reward working class and minority children if they exhibited valued cultural resources typically carried by wealthier White children. But this has been a historically unlikely reality until now. Educational institutions tout digital skills as important for achievement, and youth, at least in this contemporary moment, develop digital skills not from their parents but from their peers.

\section{DIGITAL SKILLS FROM PLAY AS CULTURAL CAPITAL}

As school-level divides in access to digital technologies have shrunk, scholars increasingly turn to studying the consequences of students' unequal development of digital skills (Hargittai and Walejko 2008; van Deursen and van Dijk 2010). Digital skills for learning, often termed new literacies, represent a way of conceptualizing the value of students' ability to use and adapt information technology to obtain high paying jobs in the twenty-first century (Castells 1998; Warschauer 2011). Research on digital skills focuses on the importance of specific proficiencies for using information communication technologies. Among these skills include both the ability to find different types of information online and communicate with others (Sefton-Green 2007; Wheeler 2009) and produce digital materials, like blogging, computer programming, and website construction (Ito et al. 2013; Peppler and Kafai 2007).

A Bourdieuian perspective would treat students' digital skills as potential cultural capital for achievement in school (Bourdieu 1977a; 1977b; 1986; Bourdieu and Passeron 1990; Lareau and Weininger 2003). ${ }^{2}$ In this view, kids' digital know-how could potentially be legitimated by teachers during day-to-day instruction. These digital skills may be a cultural resource for participation in other aspects of kids' lives, such as their youth cultures, but they would only be useful for school if institutional agents, like teachers, deem them important (Carter 2005). As the cultural reproduction argument goes, parents would transmit these digital competencies to their children and children then use those competencies in the classroom to get ahead. But this is not the present reality. The current adoption rates of digital technologies present a reconfiguration where, at least for now, parents are not the primary source of these valued skills.

Popularly referred to as 'digital youth,' today's young people have unprecedented access to, and facility with, digital technologies (Ito et al. 2009; Lenhart 2015a; Lenhart 2015b; Madden et al. 2013; Tufecki 2008a; 2008b). Traditionally underserved

\footnotetext{
${ }^{2}$ There is some tension among scholarship on cultural capital as to whether skills should be included in this category or should instead be considered a form of human capital. I follow a line of thinking advocated by Lareau and Weininger (2003) which includes (digital) styles and skills as both cultural capital. In doing so, I am thus able to observe the micro-interactional processes where children's digital styles and skills interface with institutional standards.
} 
populations, including Blacks, Latinos, and youth from low-income families, are not far behind wealthier Whites in the rates at which they adopt new technologies (Lenhart 2015a; Lenhart 2015b; Lenhart et al. 2010; Madden et al. 2013; NTIA 2001; Rainie 2011). Critically, young people learn digital skills through playful pursuits with peers. ${ }^{3}$ In a large-scale, comparative ethnographic study of digital youth, Ito et al. (2009) find that youth use digital platforms and related interactions not necessarily as a replacement for youth culture but rather as an extension of it. Through digitally mediated play, young people "hang out" with their peers online and "mess around" with digital tools necessary for using these online sites of engagement. For example, they use image, audio, and video editing software to remix and share their favorite media from popular culture, or tinker with design and programming embedded in applications online to engage in playful pursuits such as video games. This suggests that play among peers is a source of kids' digital skills. Endowed with these valued cultural resources, less privileged children may have greater opportunity for cultural mobility.

Despite the potential for cultural mobility, how might kids' digital skills learned outside of school be treated in school? Do teachers treat digital play as a source of skill or as a distraction from learning? Do they try to integrate digital play into the classroom or instead see it as a distraction from learning? Schools may discipline play in different ways. Some schools might welcome young people's digital styles as valued cultural capital. Others might treat play as irrelevant to and a distraction from the real work of learning. I turn to work on institutional factors at school to explore this possibility.

\section{INSTITUTIONAL INFLUENCES ON DIGITAL PEDAGOGY}

Education researchers point to teachers' and administrators' pedagogical approaches as the blueprint for how digital technologies are used in the classroom. These formal pedagogical orientations, which could include instructional goals, lesson scripts, and philosophical approaches to teaching, shape whether and how digital technologies are used to teach skills in online communication and digital production (Schoenfeld 2000; Stark 2000). This line of thinking is linked to federal and state initiatives that encourage integrating information and communication technologies into formal pedagogical decisions at the school-level (Dede et al. 2005; Overbay et al. 2010; U.S. Department of Education 2010). Work in this area suggests that schools must be committed to teaching twenty-first century skills with digital technology as part of its educational policy and pedagogical strategies in the classroom (Collins and Halverson 2009; Drexler et al. 2008; Ertmer et al. 2012; Schrum and Levin 2009). We may then expect that schools' commitment to digital technology would determine whether kids' digital skills are seen as valuable for learning.

But social reproduction theorists argue that schools impose an informal set of expectations that create stratified entry points for children irrespective of the cultural

\footnotetext{
3 I use 'play' in this paper to refer to kids' pursuits with their peers, and specifically how in this contemporary moment children develop digital skills from digital youth culture and not from their parents. Historians and philosophers have explored other facets of play, including its use in norm acquisition and even politics, but I do not explore those themes here (Henricks 2012; Huizinga 1955).
} 
resources they bring with them to school (Bowles and Gintis 1976). They argue that teachers share beliefs about the labor market prospects of their student population, and then enact these beliefs during instruction through "discipline." The term refers not simply to correcting students' bad behavior, but describes an institutional process that determines appropriate behavior and internalizes norms in students (Bowles and Gintis 1976; Foucault 1975; Freire 1996). In other words, teachers' lessons are shaped by a collective "common sense" about their student body and their potential, and may determine whether digital play is seen as a valuable part of learning in the classroom.

Existing work suggests that race and class are intimately connected to teachers' assumptions about their students' trajectory in the labor market, which in turn shapes their day-to-day lessons. Race- and class-inflected stereotypes are collectively shared by teachers at the school and can be traced to the school's history in the outlying region it serves (Carter 2012; Kruse and Louis 2009; Lewis 2003a; 2003b; McDonough 1997). For example, this literature argues that teachers typically have low expectations of students at schools with predominately working class Latino youth because they, in part, assume that these children are destined for working class jobs (Anyon 1980; 1981; Bobo 2001; Farkas et al. 1990; Horvat and Antonio 1999; Irizarry 2015). Stereotypes about Latino children as coming from unstable homes and prone to delinquency inform low expectations for achievement during lessons (Rios 2011). Studies report that teachers generally have higher expectations of students at schools with wealthier White and Asian youth (Anyon 1980; 1981; Lee and Zhou 2015). Upwardly mobile Asian-American youth benefit from being seen as model minorities bound for success as a consequence of racial affiliation, whereas White students, in particular, benefit from Whiteness' invisibility and their achievements are seen as individual successes rather than be attributed to race-based stereotypes (Lee and Zhou 2015; McIntyre 1997).

Race- and class-based perceptions of students' labor market potential may also extend into how teachers evaluate kids' digital skills for learning. In conversations with other faculty and administrators, teachers develop a shared understanding of their student's future career prospects that shapes how they teach students (Moller et al. 2014). We would expect that teachers at schools serving working Latino students would not integrate kids' digital skills as they would not be seen as valuable for working class jobs. Teachers serving middle- and upper class Asian or White students, however, would instead treat their students' digital skills as valuable for learning to become future leaders and managers.

Through a comparison of three middle schools that vary by student class and race, I find that students' digital skills are differently transformed by teachers into cultural capital for achievement. Teachers do this through a disciplinary process by which they communicate to students whether their digital expressions matter for learning or not. Only teachers at the school serving mostly wealthy and White children position their students' digital skills as important to education, while teachers the two others schools serving less privileged children of color treat these same digital skills as irrelevant or threating to learning. This study builds on the existing literature by illustrating that schools unevenly legitimate kids' similar cultural displays and in ways that matter for achievement.

RESEARCH METHODS 


\section{Research Sites and Samples}

Heathcliff Academy (all names are pseudonyms), a private middle school, Sheldon Junior High and César Chávez Middle School, both public middle schools, are located in suburbs in Southern California. Scholars contend that middle school is an important experience for students for both psychological and sociological reasons: first, it is portrayed as a critical period for students' identity development and a predictor for later academic trajectories in schools (Kinney 1993); second, tracking is unlikely to structure student experience as it typically does later on in high school (Gamoran and Mare 1989); and third, middle school is increasingly targeted as a time for teaching key digital skills like online collaboration and digital production (ITSE 2007).

This project was entirely conducted under the auspices of University of California-Irvine as part of a study of both the challenges and opportunities of using digital technologies in education. At the beginning of the project, I emailed all public middle school principals within a thirty-mile radius of a region of Southern California describing the study and asking for a preliminary meeting to talk about their participation. I then followed up with phone calls to these principals, and secured ten meetings. During these meetings, I asked about their school's available digital technologies and answered any questions they had about the project. Ultimately, four public schools were interested and I selected two that shared similar availability of high quality digital technologies for teaching except for key differences in student demographics. I recruited participation from the private school through a meeting I secured through a colleague who knew teachers at the school.

Ideally, a study design of this nature would include schools for comparison where key variables, including school type, technology resources, and student race and class, are not confounded. To address some of these concerns, I first made sure that the public schools I selected were useful for comparison to the private school. These three schools not only had access to high quality digital technologies for teaching but they also were each very committed to using them during instruction. Each school had active faculty initiatives to support instructive technology use and to assess and integrate them into dayto-day lessons for every subject. This minimizes the likelihood that school-level digital divides, in terms of not only access but also institutional priorities for use, would shape the results. During the period of this study, California was in the middle of a several-year rollout of new computerized state tests for their middle school students. I benefitted from a state-level transitional period during which the public school teachers said they were not pressured to constrict their curriculum due to testing. Every interviewed teacher at the public schools said that whereas in years past they may have worried that test pressures interfered with the flexibility of their teaching, they did not worry at all about testing at the time of the study. Lastly, while it would have been ideal to compare three schools were race and class were not confounded, this is atypical. Schools are overwhelming similar in configuration to those included in this study.

Teachers, administrators, and staff at both schools are primarily White, middle class, and female, similar to the profile of teachers for these grade levels nationwide (Feistritzer 2011). Students, however, differ demographically by school. Heathcliff Academy students are primarily wealthy and White, with a small percentage of Asian- 
American children. The annual cost to attend is over $\$ 20,000$ a year and they offer no scholarships. Although I do not have representative data on parent education levels, interviews with administrators and youth suggest that students' parents are typically college educated and occupy senior level positions at successful companies. Sheldon Junior High students are typically middle-class and Asian-American (typically first generation Chinese-American and Korean-American youth), and a smaller percentage of students are Latino (typically first or 1.5 generation Mexican-American youth). César Chávez Middle School students are largely working-class and Latino (generally first or 1.5 generation Mexican-American youth). Student interviews suggest that parents at Chávez are generally not college educated, whereas Sheldon parents are. Whereas much existing work focuses on stratification patterns within schools, this sampling method compares teaching across schools with different student populations. Exploring stratification processes that occur between schools is particularly valuable because schools are often racially and socioeconomically segregated because of neighborhood composition (Orfield and Gordon 2001). See Table 1 for school characteristics.

Table 1: School Characteristics (Percentages Noted)

\begin{tabular}{|c|c|c|c|c|c|c|c|c|}
\hline & \multicolumn{5}{|c|}{ Race-Ethnicity (\%) } & \multirow{2}{*}{$\begin{array}{c}\text { Family Income } \\
\text { Free/Reduced } \\
\text { Price Lunch } \\
(\%)\end{array}$} & \multirow{2}{*}{$\begin{array}{c}\text { Class } \\
\text { Sizes } \\
\begin{array}{c}\text { Number } \\
\text { of } \\
\text { Students }\end{array}\end{array}$} & \\
\hline & White & Asian & Latino & Black & Other & & & $\mathrm{S}$ \\
\hline Heathcliff Academy & 74 & 14 & 3 & 1 & 8 & 0 & 20 & \\
\hline Sheldon Junior High & 15 & 60 & 16 & 3 & 6 & 10 & 26 & \\
\hline César Chávez Middle & 5 & 3 & 80 & 8 & 4 & 87 & 27 & \\
\hline
\end{tabular}

Source: Data obtained for César Chávez Middle and Sheldon Junior High from publicly available School Accountability Report Cards (SARC). Data for Heathcliff Academy obtained directly from administration.

I used publicly available school report cards to identify school-wide characteristics to provide additional information, including average class sizes and frequency of disciplinary issues, student race-ethnicity, social class, English language proficiency, and teacher graduate school training, teacher technology training, and teachers' years of experience. During interviews with teachers I obtained their raceethnicity, training, and years taught, self-reports of technology skill, and I used interviews with students to identify their race-ethnicity. Teachers report a comparable spectrum of technology skill at each of the schools, with most saying they are proficient and a few at each school saying they are experts. This same spectrum of teacher skill, as well as other factors such as teacher training and years of teaching, was reported at each of the schools (Appendix 1).

\section{Data Collection}

This comparative study included in-school observations and in-depth interviews with teachers, administrators, staff, and students. Table 2 provides details. The IRB permitted me to observe day-to-day life in participating middle schools, including classroom observation as well as other contexts studied in other school ethnographies such as hallways, faculty lounges, and lunch and recess areas. At the beginning of the school year 
I began by interviewing as many teachers, administrators and staff as possible at each of the schools. These interviews occurred in their offices. All interviewees in the study received a study information sheet before interview and were informed that the study was about understanding the use of digital technologies and the challenges and opportunities associated with digital technology use at school. Interviews lasted roughly forty-five minutes to an hour each. No gifts or monetary compensation was provided to any study participants.

Table 2: Interviewed Teacher and Student Sample Characteristics (Percentages Noted)

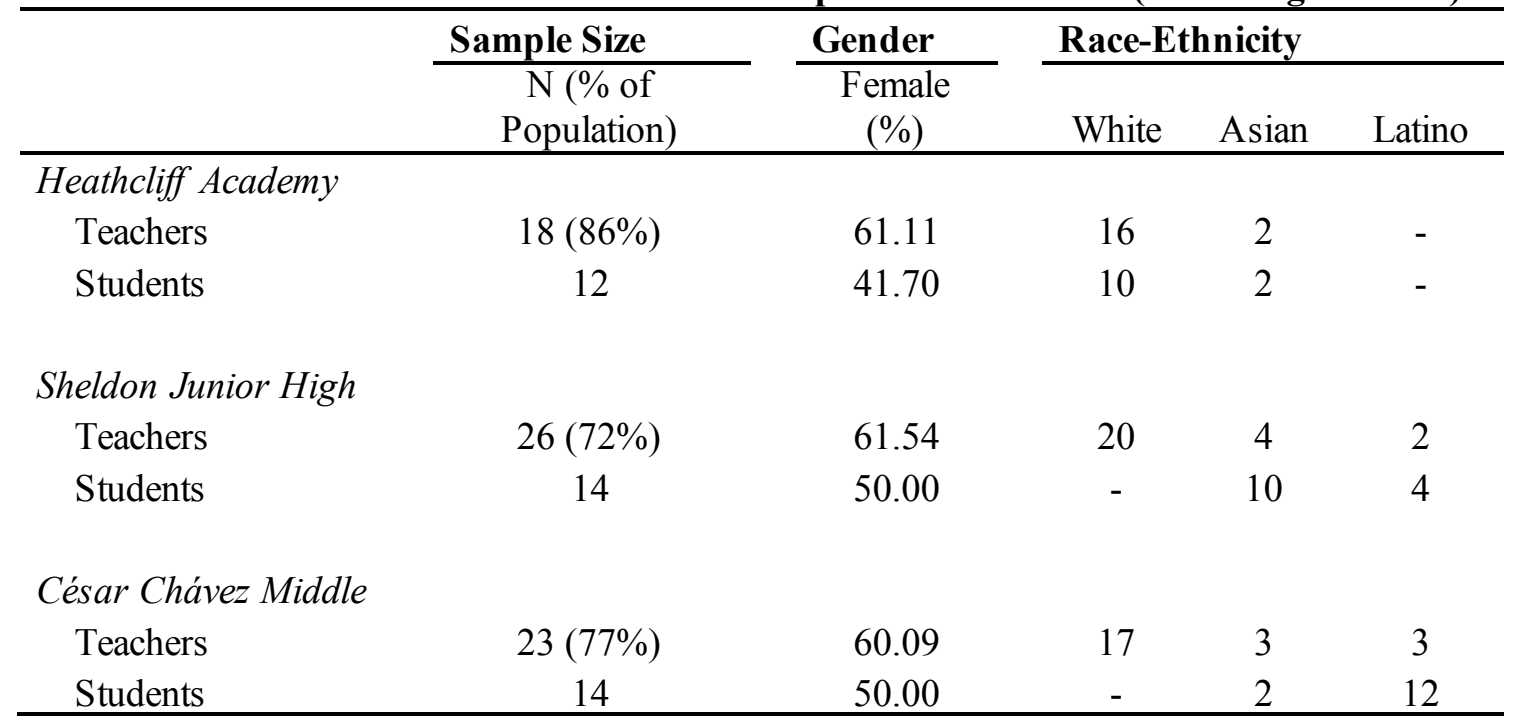

I observed the classrooms of the teachers I interviewed until the end of the academic year. I typically spent a full day at one school (approximately 6 hours), and then a full day at a different school, and did this for, on average, four days of each week. At the start of each week, I put participating teachers' names into a computerized randomizer and observed their classes, in that order, throughout each week. This method allowed me to more effectively capture day-to-day life at the school by ensuring that I not only spent equal time with teachers but also observed during different times of day and with different classes of students.

Many school ethnographers become integrated into the school setting first by building rapport with youth. I became integrated first through my relationships with the teachers at the school. I learned during my work that teachers at each school were quite used to others observing their classrooms, including other teachers and researchers, and this helped to acclimate me to the setting. I also note that, although I cannot test this assumption, my status as a White, geeky male may have helped me to integrate into each of the school settings. We know from other scholarly work that men in female-dominated spaces are given "passes" for their social etiquette missteps as well as other privileges in their setting of work (Williams 1993). Teachers would often warm up to me after they learned that I studied technology, and saw me as a sounding board for their gripes as well as a makeshift assistant when they struggled with an issue using a digital tool. When I asked teachers to describe their students, White faculty very willingly shared racialized, classed, and gendered notions of their students in considerable detail. I noticed, too, that 
they would seem less willing to share such information if a student of color entered the room, and so I made a point to conduct my interviews with teachers in private settings, where possible.

Over time, students would notice that I was a fixture in their classrooms and would inevitably approach me to ask who I was and what I was doing there. I used these moments as early opportunities to learn about the students and connect with them. Teachers and students referred to me by "Mr." but I referred to myself by my first name with students when I interacted with them. I also avoided making value judgements verbally about student behavior, and was fortunate to have not observed any physical altercations between students during the year I attended that may have warranted interjection.

As part of my fieldwork, I not only observed classrooms but also attended faculty meetings and workshops, parent teacher and after school events, and I also observed in faculty lounges and in student lunch areas. During observations, I used ethnographic jottings to document interactions I observed and to record pieces of dialogue from informal conversations with teachers and students. After each observation, I expanded these jottings into detailed field notes. I did not solicit or include data obtained by interacting directly with students online (i.e., texting). Although some students did want to communicate with me across digital platforms, I felt it was too risky given some of the sanctions students at one participating school received for communicating online with their peers. However, I did collect data collected through observations online on websites hosted by each of the schools, including faculty websites and internal communications tools shared with me by teachers or administrators.

During the last few months of the study, I selected one "ideal type" eighth grade classroom at each school where the observed school-level patterns were strongest, and I randomly selected half of the students to interview. While unable to interview most of the students at the school as I did for the teachers and staff, this sampling method allowed me to speak with youth in classes that were best fits for the school-level themes I identified. The IRB permitted interviews with youth per protocols established by the school. This meant largely interviewing students in a quiet corner of a classroom or just outside of a classroom at a picnic table. Two schools decided to email parents to notify them this research was occurring at their school. All students agreed to be interviewed.

Although many ethnographic studies of schools focus on one school or even just a few classes over a number of years, I selected multiple schools for comparison over the course of one academic year. While I could not continue my work in these schools after one year, I found that my data collection efforts yielded school-level patterns.

All interviews were audio-recorded and transcribed. I used these interviews to document the various messages teachers and students received about appropriate forms of instruction and learning. All teachers were asked to describe the typical student, parent, and teacher at their school, to reflect on their teaching practices with and without digital technologies, and to comment on students' digital competencies. I asked students to describe the typical student and teacher at their school, to comment on their experiences with digital technology, and to narrate their experience as students over the course of middle school. I then coded these open-ended responses and used them to compare respondents' attitudes toward students and orientations to learning across schools. I 
present some of these comparisons to highlight patterns documented in the larger ethnographic study.

\section{Data Analysis}

I conducted an ongoing process of data analysis, regularly reviewing field notes and interview transcripts and writing analytic memos (Emerson, Fretz, and Shaw 1995). I used the memos to identify emerging themes in the data, discuss connections to existing research, and pose additional questions. After creating a preliminary coding scheme from themes in the memos, I used Dedoose, a mixed methods coding application, to code sections of field notes, interview transcripts, and documents. Although obscured from my view while coding, each document was linked to a quantitative data point with sample characteristics (i.e., school name, class size, years of teaching, student race-ethnicity). This method allowed me to code freely for themes and afterwards sort coded excerpts by these characteristics to clarify comparisons and identify disconfirming evidence.

\section{GENERATIONAL SIMILARITIES IN DIGITAL PARTICIPATION}

\section{Student Hardware Access}

Existing work over the last decade indicates that digital technologies are prominent in the lives of today's young people regardless of family origin (Lenhart 2015a; 2015b). Consistent with these studies, the sampled students at Heathcliff Academy, Sheldon Junior High, and César Chávez Middle School shared a similar baseline of both technology access and use of digital platforms. They pursued many of their interests online with peers. Although it may be premature to suggest that each student population was perfectly equal in both home access and use of digital technology as part of their youth culture, I nonetheless found many key similarities. Among all interviewed students, $97.5 \%$ had regular access to one or more up-to-date computer or laptop, iPod, or internetconnected video game system at home. All students had access to cell phones at home and at school, and among those $82.5 \%$ owned smartphones like iPhones or Android devices. Although I was not able to conduct representative surveys of the student body at each school, teachers at both schools conducted their own informal surveys of students and reported similar numbers.

Differences in student hardware ownership across schools were also rather small. Figure 1 shows that interviewed students at Chávez and Sheldon owned smartphones at slightly higher rates than those at Heathcliff. There were few reported differences in access to digital technology at home. These statistics are consistent with national survey data that show widespread access to digital technology among youth regardless of family origin (Lenhart 2015a; Lenhart 2015b). 


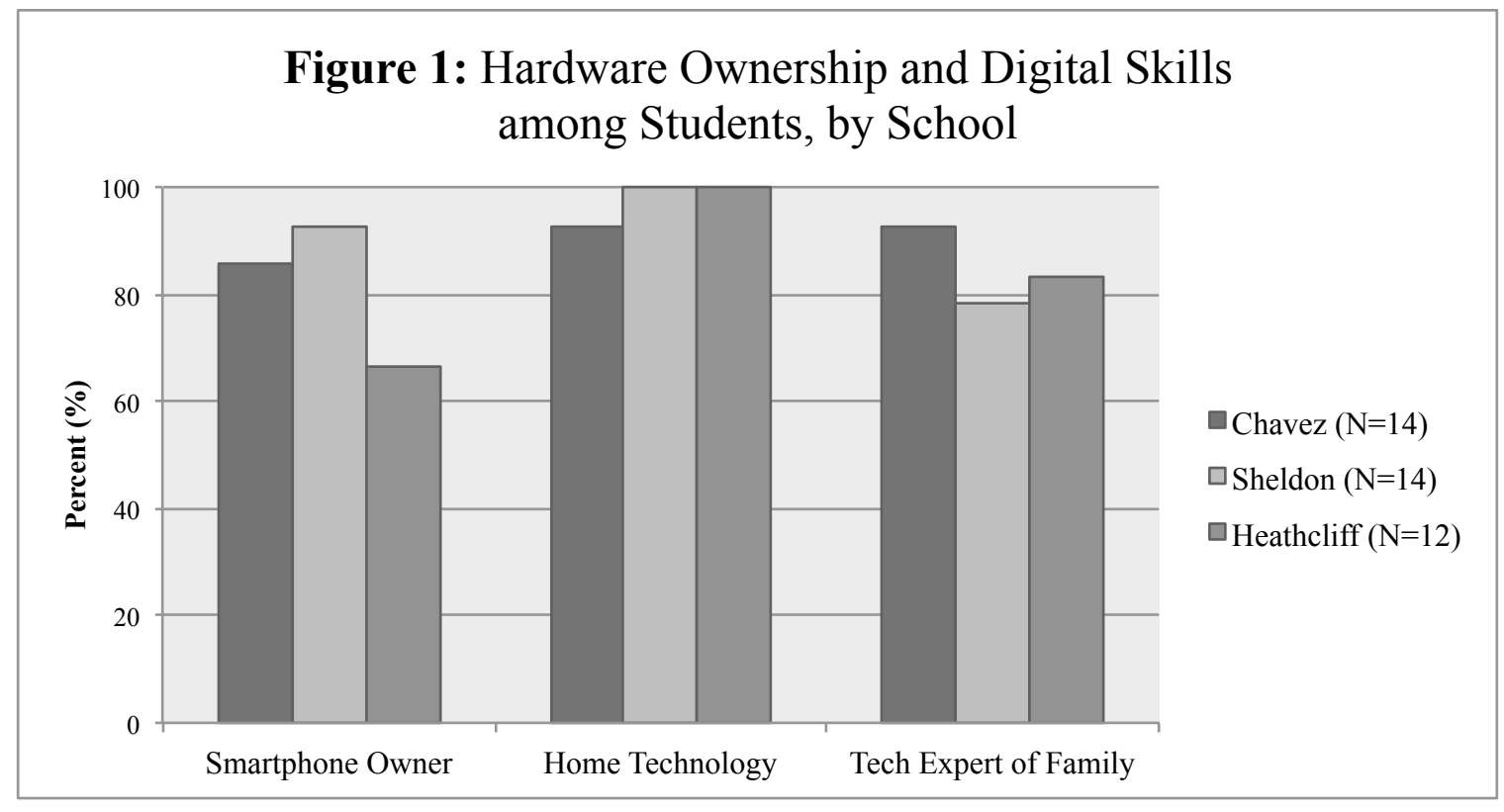

\section{Student Digital Expertise}

Interviewed students also expressed that they were primarily the technology experts of the family and did not learn how to use digital technologies from their parents. $85 \%$ of all students said they were the tech experts, and slightly more students at Chávez said so than students at other schools (Figure 1). When asked about their digital expertise relative to their families, students often laughed and asserted that their parents knew very little about technology. For example, Daniel (15 years old, Asian), a student at Sheldon, said, "I'm the techie of the family. My dad is good but I'm better." Maggie (13 years old, White), a Heathcliff student, argued that she is better at technology than her mother and father, too: "I know how to use programs that my parents don't even know how to use." And at Chávez, Bailey (14 years old, Latina) said that she and her older brother are both skilled. "He and I are both the tech experts of the family," she said. "We fix computers and programs together." Although the digital environments and resources might still vary by family of origins, students at each of the schools were by and large more "techie" than their parents or guardians, and indicated that they were not taught digital skills from their parents. Instead, they said that they developed digital skills through their play with friends online.

\section{Digitally Mediated Play among Peers}

Students nearly all developed digital facility through playful pursuits with peers. The kinds of online activities they participated in and skills with digital technology they developed are consistent with existing work on digital youth culture. I found that youth enjoy communication through social media and digital production. In what follows, I provide examples of these activities from students at each school to illustrate the generational similarities in digital youth culture from these samples.

Nearly all sampled students at each school used social media to share text, image, and video-based communications with their peers. "I use Kik and Instagram on my 
phone," said Anthony (13 years old, Latino), a student at Chávez. "I talk with my friends and keep up with what they're doing on my phone." Cordelia (14 years old, White), a student at Heathcliff, was an avid social media user: "I use Instagram and Snapchat mostly. I love Snapchat, and texting. It's how I stay in touch with my friends." Andrew (13 years old, Latino), a student at Sheldon, also used Instagram and Snapchat. "I use Instagram and Snapchat almost every day," he said. "Sometimes we record silly videos of ourselves and send them to each other. Students used social media to send messages using a variety of new media, including text, image, and video content that they developed using their phones or other hardware at home. But they also used social applications to set up activities. For example, Anne (14 years old, Asian), another student at Sheldon, used social media to keep up with her friends and coordinate hanging out. "My friends use texting and other apps like Kik to plan things and hang out in person, too." Consistent with studies of digital youth that find generational differences in digital participation, youth at all three schools used texting and other media-rich communications applications to "hang out" with friends and participate in their peer cultures. These practices also help the development of digital skills like facility with digital platforms and online communication.

Digital production was the second type of digital activity that students at each school pursued with their friends. Although social media use does require that youth develop their ability to communicate across digital platforms, digital production demands considerably more technical knowledge. For example, a number of youth pursued creative production through software development. Several youth "jailbroke" their mobile phones to program their own applications. "I jailbreak my iPod, and I tinker with it a bit," said Daniel (15 years old, Asian), a student at Sheldon. "I get into the back-end of the programming. Nobody really knows I do that." Hacking and remaking parts of one's own phone requires knowledge of software programming. Danny (13 years old, Latino), a Chávez student, also hacked some of his video games to accomplish specific goals. "When I want to get money on a game sometimes I will mod it," he said. "You download this APK stuff so the game gets tricked into giving you money. It might help me some day if I want to become a hacker! Ha. Or maybe a programmer, who knows." Students' digital production activities, including online writing and hacking, are among the most popularly idealized digital skills in research on new literacies.

But digital production does not need to be quite as technical as jailbreaking, and students at each school used image and video editing for creative purposes, as well. Sarah (15 years old, Asian), a student at Sheldon, liked creating and sharing artistic pictures she takes on social media with her friends: "I think social media is super creative. If you want to learn how to do it, that is. I had to figure out how to download the right photo editing apps to get the pictures how I wanted before I shared it on Instagram." Nathan (14 years old, White), a student at Heathcliff, said that he liked to make short videos that he uploaded on an app called Vine. "Me and my friends will record each other to make little short stories that we think are funny," he said. "We'll upload them on Vine, which is like an Instagram just for video. We're trying to get more followers but we like what we've made so far." Richard (14 years old, Latino), a student at Chávez, produced music with his friend. Some students also pursued design-oriented games, like Armin (14 years old, Latino), a Sheldon student, who spends a lot of time playing world-creation games. "I like building games like Minecraft where you can build whatever you want," he said. "I 
feel like I'm developing the architecture for what houses would look like in real life, or even bridges." These digital skills align with scholarship on new literacies, including improvement as computer programmers and designers, and editors and producers of media like audio, images, and videos (Ito et al. 2013; Peppler and Kafai 2007).

In this section, I have shown that students in this study shared a baseline set of digital skills that they developed mainly through their youth cultures. While there may be some differences between youth at each school in terms of the interests they pursued online, there were not dramatic differences by school in these baseline capacities with online communication and digital production. In what follows, I illustrate what happened when students brought these baseline skills developed through play to school. Even though teachers themselves were often less skilled with digital technology than their students, teachers disciplined students' digital skills in distinct ways.

\section{DISCIPLINING PLAY AT SCHOOL}

\section{Steve Jobs Potentials at Heathcliff Academy}

Ms. Cramer, a seventh grade science teacher at Heathcliff, had a PowerPoint slide displayed at the front of her class that showed a mostly empty grid of the periodic table of the elements. "Good morning, scientists!" she exclaimed to the class. "Remember that today we're going to play a game where you have to guess the right element based on its atomic number." James, a student in the back of the class, simultaneously raised his hand and spoke. "Ms. Cramer, I have an idea for this!" he said. "I was playing a game on my iPad yesterday that has the periodic table that I think we could do instead." Ms. Cramer walked over to his desk and looked at the game on his iPad as he explained how it worked out loud. She asked a series of questions, nodding as the youth tried to answer. "Is it free to download?" "Is it easy to set up?" After a couple minutes, she was sold. "Okay everyone, as much as I love a good PowerPoint let's give this game a try. Go ahead and download it on your iPad." The class cheered. "James, you're our IT guy if anyone has a problem downloading."

Although teachers at each of the schools typically described themselves as less skilled with technology than their students, teachers perceived the value of students' digital youth culture differently by school. At Heathcliff, teachers saw students' own interests online as valuable, if not essential, to academic achievement. Mr. Crouse, the school technology lab manager and technology integrationist, said that ideal uses of technology bridged students' lives with school:

I always use the example of Steve Jobs going to his garage and tinkering around. Why can't the garage be at school? There's value in having school be a place where kids can come in, bring what they know from their own lives, and have their eyes light up with possibility and say, okay, I see maybe something I can do here and I can become passionate about.

In this view, Mr. Crouse saw students" "garages," or the kinds of activities they do outside, as an important part of learning in school settings. Thus, integrating these practices with schooling was the way to cultivate the next Steve Jobs. Further, when he 
purchased new education technologies for Heathcliff, like iPads, he used this integration approach to frame its use at school. "The iPad is not really a device - it's a portal. What you need is for every student to have a portal into web based solutions," he said. "It's their textbook, their agenda, a notebook, a research tool, and a camera into their lives. It's all those things. 1-to-1 isn't about just handing someone a computer. It's creating a portal at school." Typically, 1-to-1 refers to a kind of education reform where each student is provided with a technology for learning, like a laptop or an iPad, but here Mr. Crouse described the reform rather as a "portal" for engagement. This portal metaphor operated at Heathcliff as a translational device for teachers to actively recognize and integrate students' digital forms as valuable cultural capital for learning at school.

Other teachers at Heathcliff also adopted this "portal" approach that blurred digital youth culture and school, and repeatedly asserted that their students bring with them to class many useful technology skills. Mrs. Kaufman, a sixth grade Spanish teacher at Heathcliff, said that students picked up iPad use in class very quickly. "It was seamless. I said, 'abran sus libros en el iPad a la pagina cincuenta' (open your books on the iPad to page fifty)." The students just did it, no problem. It's like they already know how to do everything because they play around with this stuff with their friends." Mrs. Lawson, a sixth grade History teacher, also acknowledged that their students have technical facilities that come from their youth culture. "These kids are in a technology age, it's just their typical way to communicate. They love iMovie and they come up with amazing videos on their own for class. Most of them are comfortable with that." Teachers described their students as already proficient in uses of technology as a result of their peer-driven participation online. At Heathcliff, faculty seemed to subscribe to the view that the digital skills acquired from hanging out with friends online have potential for learning. Teachers saw connections between students' digital skills and school-based learning.

Heathcliff teachers also described trying to integrate digital youth culture into their instructional philosophies and practices as part of a learning agenda. Ms. Pryce, an eigth grade Language Arts teacher, argued that she and her students mix their different skill sets to create a productive learning experience. "Oh yes, they are tech savvy, just like that term 'digital native,"” she said. "They're raised with these technologies and so they are definitely good at using them at school. But it's my job as the old fogey 'digital immigrant' to take what they know and help them here." Ms. Pryce used the terms "digital native" and "digital immigrant" to position her students as budding technologists and herself as an integrationist of digital youth culture in school. Mrs. Cramer, the seventh grade Science teacher mentioned earlier, commented on how games that students play can be productive for school, too. "They're comfortable with many of the apps and programs they are used to, and that can really help with school. I use a lot of games, like, we have one game a student found to memorize the periodic table. I say why not?"

Teachers like Mrs. Cramer saw the value of video games for learning, and she encouraged youth to find ways to blend these practices during science classes. In another example, Heathcliff's art teacher, Ms. Kober, reflected on how students created art projects that get connected to social media. "One of my students had this little surfer guy he made out of clay and was using his phone to create a stop-motion claymation video and then put it on Instagram to share with his friends," she said. "They all got a kick out of it. He was doing something creative and wanted to share it, which I think is a big part 
of doing art." For Ms. Kober, student uses of technology bridged school activities with digital youth culture for a more engaged learning experience. Heathcliff teachers' disciplinary orientation to play thus construed their students' digital youth culture as valuable capital for achievement.

Teachers at Heathcliff required that students practice integrating their digital forms and ideas at school, thus carving a path to transforming digital youth culture into capital for learning. For example, as part of their training at the school students were required to have a number of opportunities to "tell their story" through the use of digital technologies before an audience of their peers who then ask them questions. In interviews, teachers joked that when students first start out doing this ritual during their first year they are so nervous that they, in the words of Mrs. Lawson, "stand up in front of the interactive whiteboard and cry as they talk about their family dog." Over time, however, students developed comfort talking about themselves in class and before their peers and instructors. This was essentially a process of legitimation, as students were compelled to develop comfort and facility with seeing their own digital practices as relevant and important to the school setting.

In one such class, I observed sixth graders "telling their story" to their peers and instructors. The way they did this was by requiring students create their own online media, including photos and video, and using it to design presentations to share with the class. As part of an assignment that integrated Language Arts, art, and technology, students were presenting a project that required them to design a PowerPoint presentation about themselves. They were required to take pictures or video outside of class, with their family or with friends, and creatively integrate this new media into the presentation. “Jessica, you're up!" said Mrs. Kober. A young woman, hands to her side, sheepishly got up out of her seat and scooted up to the front of the room with a USB stick in her hand. She plugged the portable drive into the computer connected to a projector screen in the front of the room, and within moments a slide covered the wall with a picture she took of her family. She added images she found from the internet to the perimeter of the slide, including a photo of cats and a softball. "Hi everyone, I'm Jessica and I this is my Mom, my Dad, and me," she murmured. "Jessica, you're doing great but be sure to speak up," said Ms. Kober. Jessica tapped the screen to move to the next slide, and tried to speak a little louder: "One of my favorite things to do is play softball!" She tapped the screen once more, and images of a baseball and baseball bat appeared and began to animate. The baseball swung and hit the ball, and it flew across the screen. A student raised their hand: "How did you make the ball move like that!?" Jessica smiled. "I figured out that you can have two pictures on the slide do different things, so I made the baseball picture swing by itself and then made the ball move on its own once it got hit." At Heathcliff students were required to practice creating their own online media and tinkering with the tools to edit and design assignments for class. Heathcliff constructed many learning activities as successful if they blurred the lines between students' interests and schooling.

In addition to structuring lessons that facilitated students' own creative production and collaboration at school, Heathcliff also provided students opportunities to integrate their own digital forms into the character and image of the institution. For example, students gave presentations at the beginning of Ms. Kramer's eigth grade science class for a project about environmental awareness. Jimmy was at the front of the screen presenting a video he produced on the topic. In the video, Jimmy combined multiple 
forms of media that included his own video recordings of his peers as well as pre-existing video created by the school administration to talk about environmental awareness. As part of his video editing process, he blended together video snippets of a pre-recorded speech by the school principal (downloaded from the school website) with his own recordings of his friends parading around campus picking up waste for recycling. He added to the background music a popular song, and included titles showing the names of the actors that animated across the screen when those people appeared. I later learned that the school decided to make Jimmy's video part of the promotional material for the school since it got more attention than their other formal productions. Teachers at Heathcliff not only transformed their students' digital skills into valued capital for achievement, but they encouraged students to take the reins over what counts as achievement. Jimmy's video, which remixed school and youth culture together to create something new, became a representation of the school.

Interviews with Heathcliff students illustrated that by the end of eighth grade they came to see school as a malleable setting where they can bring in their own digital interests and skills for classroom success. Andrew (14 years old, White), reflected on how his approach to using digital technology at school shifted since he enrolled in fifth grade: "Teachers here really force us to get comfortable showing off our online projects to the school since we start here. It's nerve-wracking at first, but eventually you learn it's kinda fun. Teachers make you feel good for sharing your ideas." Heathcliff teachers' instructional practices encouraged students' growth as digital producers at school, encouraging them to develop enough comfort to conceive of messing around at school as welcome and fun. Further, when students brought in the digital forms from their youth culture to school students described it as a legitimating experience that gave them authority over their own curriculum. Ken (14 years old, White), explains:

For class last year we had an assignment to describe city life. The assignment teachers gave us was to write a normal paper, but me and my friends were like, 'Hey, let's build a city on Minecraft.' The teacher liked our idea and loved the finished product, it turned out really well. I ended up being able to use Minecraft for class. Teachers may not understand it but they let us bring stuff like that in. Minecraft is after all a creativity game.

Heathcliff teachers disciplined play by integrating students' digital skills into the learning agenda. Students, like Ken, were socialized into seeing school as an environment in which they will be rewarded for playing around with digital technology. Although the school did reprimand the few students who played violent video games at school, teachers by and large sought out opportunities to transform kids' digital capacities into cultural capital. This was representative of a pattern whereby teachers communicated to students the value of the digital skills they acquired through play, which transformed digital competencies into cultural capital for achievement.

Heathcliff faculty disciplined play by transforming kids' digital skills into cultural capital for achievement. But where did this disciplinary orientation come from? Like the other schools in this study, Heathcliff faculty and administrators were committed to a formal pedagogy that integrated digital technologies into lessons. But Heathcliff faculty 
shared a set of norms that emerged from their relationship with students' parents that informs the perceived value of students' digital technology use at school.

Every faculty member and administrator at Heathcliff described the various academic standards that they imposed during instruction, but they all expressed that ultimately it came down to impressing parents. "Most of them are pretty affluent," said Mr. Filippo, a seventh grade Social Studies teacher. "They are all very successful, and expect their kids to succeed, too. When we teach these kids in class we're always thinking in the back of our minds what their parents might say." This mentality among faculty of serving elites shaped their workplace dynamic. Teachers described their colleagues as smart and capable, but an underlying tension of existed among them related to who pleased parents the most, and especially when it came to using digital technology. In the words of Ms. Lawson, a sixth grade history teacher, "the feeling is if these kids don't end up getting into the best high school or college after here, it's pretty much our fault." This workplace dynamic oriented teachers to think of themselves as attendants to their gifted students.

Although parents put considerable pressure on teachers, the expectation that teachers treat students as elites was shared among faculty and enforced among one another at the organization-level. For example, I sat in on a faculty meeting where teachers and administrators discussed available budgets for their instruction. Mr. Banks, an administrator for the school, led the meeting:

Mr. Banks: As you all know, the Spring Gala is a major part of the budget that we get to pay for school supplies and other events here. Remember that we had a smaller budget last year because of poorer parent turnout. We're working with the principal and marketing to do a better job, but we still need some ideas.

Ms. Kaufman: I think we need to do a better job sharing with parents all the amazing things our students are doing. I mean, look at Dylan's yearbook online, or even some of the videos my students make for their assignments.

Ms. Richards: Great idea - and we need to do more of that, turn the great work our students do into activities that can be shared.

During the faculty meeting, teachers emphasized the need to not only teach students but make highly visible their students' achievements as part of not only a pedagogical process but also economic need. Faculty communicated similar messages to one another in less formal settings, as well. I routinely hung out in the faculty lunchroom that, incidentally, was also used by parents who visited during the school day to volunteer, drop off food, and coordinate events. "Those kids come to me straight after his class and are half asleep," said Ms. Daniels, the school art teacher, to Mr. Gates, the school music teacher, over lunch. "Students tell me they don't learn anything from him, and then I'm the one who has to spend the first thirty minutes of my time trying to wake them up." $\mathrm{Mr}$. Gates shook his head, concerned. "That's not helping those kids, that's not how we do things here." At Heathcliff, faculty shared an understanding that students come first above all, that their students deserve an elite education, and that their students' talents need be showcased publicly. Although a full explication of how teachers racialized 
students at Heathcliff is outside the scope of this paper, teachers did not seem to differentiate between their White majority and Asian minority student body in how they treated the transformation of students' digital knowledge into cultural capital. Parents' high involvement in the curriculum, along with their appreciation for twenty-first century digital skills, shaped how teachers disciplined play by transforming kids' digital skills into cultural capital for success.

\section{Risky Hackers at Sheldon Junior High}

Whereas at Heathcliff students' digital forms were turned into valued capital for achievement, teachers at Sheldon actively policed the boundary between digital youth culture and school. They perceived students' digital forms as serious threats to learning. Teachers' orientation to students' digital play came from shared perceptions that their status as middle-class, Asian-American students signified cutthroat overachievers. Those perceptions seemed to be associated with an approach to digital technology that positioned students' digital skills as unwelcome during instruction. As a consequence, teachers only used digital technologies for high stakes activities (lessons that primarily result in students gaining high rewards or great punishment) and traditional exams rather than to teach digital skills. Sheldon students reported that this high stakes nature of the classroom was anxiety-laden, and encouraged them to achieve not by integrating their digital skills into the curriculum but rather by doing well on traditional exams.

Teachers at Sheldon Junior High drew upon class- and race-based stereotypes to construct their students as risky hackers. They believed that their students were smart and naturally good with technology because they are Asian, but also posed threats because competitive "Tiger Moms" raised them. Ms. McDonough, a seventh grade language arts teacher, explained:

The typical student here is pretty high achieving. Mostly Asian and very good at taking tests but not very good independent thinkers. I think they have a lot of fear of doing something wrong because they're raised by these Tiger Moms who will not let them out of the house unless they do well. We have some very gifted kids who are already taking the SATs and scoring high, but they lack some of the humanity kids this age should have because of how they're raised.

Like Ms. McDonough, Mr. McNally expressed frustration that his eighth grade students were raised to be so test-focused. "They're only as good as how they are on a test," he said. "In Asian culture, their livelihoods are about tests. The benchmark in China is about tests. We're creating people who can't think or can't problem solve, but they're good at tests." Teachers also expressed that their students' cutthroat orientation extended into major disciplinary issues. "We've had a bunch of suspensions this year because these Asian kids are so good at using technology that they hack our online system," said Ms. Finnerty, an eighth grade Science teacher. "One student broke into a teacher's website and locked her out. They'll do anything to do well." At Sheldon Junior High, teachers expressed that parents pressured their children to do well in school, but I found no differences in the content of the requests by similarly aggressive parents at Heathcliff. Thus, despite possessing similar cultural resources, Asian parents did not reap the same 
rewards as Whites (Lareau and Horvat 1999). Rather, teachers drew on racialized imagery of Asian students as upwardly mobile and cutthroat students who were intelligent and college-driven but also potential threats. Digital proficiency was seen as what makes Asian students threatening. While research suggests that some Asian students are seen as model minorities because of their orientation to success, I found that digital play here is seen as an unwelcome form for learning in the classroom (Lee and Zhou 2015).

Teachers at Sheldon not only doubted the value of digital skills that come from students' youth cultures but they also saw those skills as threatening to successful schooling. For example, Ms. Ullman, a seventh grade history teacher, believed that social media is not only frivolous but that it is also a distraction from learning. "Twitter doesn't help them with tests. Facebook doesn't help them with essays. It prevents them from focusing on important tasks in class and on homework," she said. "They can text, but can they type in MLA format? No." Teachers also believed that students' digital play at school would lead to disruptive hacking, as in Ms. Finnerty's comments about student hackers mentioned earlier. At Sheldon, teachers described the activities and digital skills developed from their students' youth culture as distractions and risks. Teachers favored traditional institutional standards and practices, including test taking preparation, essay writing, and meeting citation standards, and framed the practices and styles youth bring with them to school as diverging from the overall educational mission.

When teachers at Sheldon reflected on their instructional practices with digital technology, they described their teaching as successful only when they are able to strictly sanction signs of digital youth culture. For example, Mr. Crump, an eighth grade language arts teacher, believed that the best way to create educational success was to limit peer engagement online:

I use Edmodo, an app that looks like Facebook where I can create a community for my students online to share assignments and grade their work. But I make it so students cannot post to other students' walls. They can't communicate with their peers at all. I put on moderator privileges where I moderate every comment, or delete every comment. If they put up a question about an assignment online, it sends me a notification that they've done it and I decide whether it gets published or not. I think it makes them more focused on the task at hand.

At Sheldon, teachers restricted almost all forms of online peer-to-peer communication and collaboration as a way to protect the integrity of schooling. Another teacher, Mr. McNally, said that for his eighth grade Science class he also actively restricted youth from interacting during online assignments. "Facebook and Instagram doesn't help them with school. The school uses of technology are traditional," he said. "I would never embrace social media as part of a lesson. I don't want to let go of this control that I have because then I have to monitor more and more of this garbage. I don't want to deal with all of that." Teachers at Sheldon constructed their curriculum in ways that separated digital youth culture from school by conceiving of it as threatening and forcefully withdrawing it from learning. They did not turn kids' digital youth cultural forms into cultural capital for achievement. 
Teachers' perceptions of students' digital skills as risks informed their day-to-day instructional practices with digital technology. Faculty at Sheldon routinely created highstakes learning activities using digital technology that made students' digital sharing an anxiety-laden experience. For example, Mrs. Trunchbull, an eighth grade science teacher, led her class through a lesson on states of matter. Students each had laptops at their desk, and a projector screen was on at the front of the screen with a list of every student presently in class. Speaking through a Bluetooth microphone hanging from her ear, she projected her voice via speakers positioned around the perimeter of the class. "Draw me a water molecule in hot water." Students returned to their work, and a minute passed. "No responses? You chickens." Shortly thereafter, a drawing appeared. The sketching was not as clear nor was the molecule model finished, and the name "Aaron" was posted in bold at top. "Aaron..." said Mrs. Trunchbull, pausing for a moment. "I don't even know what to say?" Students all laughed, and Aaron was quiet and looked down at his computer. "Should we print this and put it on the wall so your parents can see it on open house day? Who says eighth graders can't do art!" In this example, Aaron's shared online creation was met with ridicule by the class. At Sheldon, education technologies were used in ways that create opportunities for high stakes learning and public humiliation if students answer incorrectly. Moreover, the digital youth cultural activities that were valued at Heathcliff, like video games, social media, and online collaboration, were strictly restricted. Teachers at Sheldon maintained their own legitimacy as authorities in the face of their students, who they saw as digitally skilled threats, by imposing sanctions for online participation that did not meet teachers' standards.

Students at Sheldon generally saw their teachers as tough disciplinarians and viewed their own digital participation at school as risk-laden. For example, Anne (15 years old, Asian) described teachers at Sheldon as "not so nice," and explained "teachers say social media is harmful." Anne saw her own social media use as "just for fun with friends," but noted that she "would never use it at school because teachers watch what you do online." Teachers' disciplinary practices had the effect of creating a binary for students between work and play, and this binary was so rigid that students like Anne maintain a "low profile" online at school to avoid punishment.

But while Sheldon students saw their playful, creative expressions as separate from the high-stakes learning in the classroom, they also came to see learning at school as high-stakes game to win. Daniel (15 years old, Asian) explained that "school is a stepping stone to get to the right place, it's not where I have fun. I save Minecraft for home." Another student, Michelle (13 years old, Asian), agreed: "Instagram is cool and everything, but...what's going to help me get into college is to do well on the tests they give us in class. School is kind of like a game in that way, to figure out how to do well. Getting the best grades you can is like a race." Students reported fearing the consequences of breaching the divide between work and play, and internalized the highstakes nature of learning at Sheldon as the reality of schooling. Rather than be permitted to integrate their digital youth culture at school for achievement, like at Heathcliff, Sheldon shut down those opportunities.

Sheldon faculty disciplined play by treating kids' digital skills as threatening to learning. But where did this come from? The more senior faculty attributed it to demographic shifts in the outlying community that occurred in the last ten to fifteen years. "We all used to be so committed to our work," said Mr. Madison, an eighth grade 
science teacher who had worked at the school for twenty-eight years. "But our students completely changed. This used to be a neighborhood with almost entirely middle class White kids. All of a sudden, Asians came in and replaced everyone. It's never been the same since." Senior faculty at Sheldon described this demographic shift as a threat to the happy life that they remember as teachers. "We used to have a lot in common with these kids," said Ms. Ullman, a seventh grade history teacher who had worked at the school for thirty-one years. "We knew where they were coming from and we knew how to support them. Today, half of them can't even speak to us in English. It's exhausting." The few teachers who shared a more positive view of their time at Sheldon were either new to the school or more senior. "This is my first job out of graduate school and I see it as kind of a fun challenge," said Ms. York, a new librarian. "If I can survive here I can pretty much survive anywhere." Among more senior faculty closer to retirement, they reflected that they could get by more easily because they cared little about the difficulties. "You really learn how to care less when you've been around as long as I have," said Ms. Wells, a seventh grade language arts teacher. "After tenure you can just kind of throw your hands up in the air and do what you know you need to do." Faculty at Sheldon, a formerly White school positioned within a neighborhood undergoing dramatic demographic changes, experienced these shifts through a lens of racialized threat that affected their day-to-day teaching.

The shared perception of students as threats was likely connected to the stereotypes of upwardly mobile Asian children described earlier, and imposed constraints on teachers' existing commitments to digital pedagogy. For example, during a faculty meeting I observed teachers and administrators talking about how to best integrate their new Chromebook laptops into lessons. "If we want to make sure these kids get into college they need to be able to focus online do well on these futuristic tests," said Mr. Leary, a sixth grade Language Arts teacher. "We need to find apps that make it easy for us to grab these kids' attention but quiz them on the same skills we know are important." Ms. Brady, an eigth grade Language Arts teacher, huffed. "And you know these kids will cheat given all the pressure they're under," she said. "We need to make sure we can track them on these things to make sure that doesn't happen." While teachers and administrators at Sheldon had high academic expectations of their students, the school's recent history of immigration was experienced as threatening to the existing racial context of the school.

In this study, race, immigration status, and class were generally confounded, and while this is the reality for most schools, I tried to document if there were any differences in how teachers at each of these schools treated children differently. At Sheldon, for example, the small population of Latino youth at Sheldon were, like Asian youth, similarly perceived as threats. I saw no differences in how teachers treated kids' digital play by student immigrant status. The small population of White students, however, were by and large ignored when teachers sanctioned students for their digital activities. This may be a consequence and privilege of Whiteness' invisibility in a context where teachers perceive their majority minority student body as hostile. But while Sheldon faculty were committed to technology use, they imagined its value through the lens of racial stereotypes about the bulk of their upwardly mobile students and what it signaled that they needed from them during instruction. Thus, teachers' predominant disciplinary orientation to play at Sheldon was that it was threatening to students' learning. 


\section{Digital Literacies for Labor at César Chávez Middle School}

While Sheldon teachers not only policed students' digital youth culture but also did not teach digital skills, I was surprised to find that Chávez taught many of the same digital skills with technology that Heathcliff students received. However, Chávez teachers imagined their students as twenty-first century laborers that relied on digital skills for working class jobs. Chávez faculty thus disciplined play by constructing students' digital youth culture as irrelevant while simultaneously teaching their own lessons about internet use, website design, and programming.

Chávez teachers shared a perception of the later life trajectory of their working class, Latino youth that seemed to inform their expectations for learning with digital technology. Teachers routinely described their students as "hard-working immigrants" from "damaged homes," and their parents as assimilating immigrants who trusted teachers with their children's education. Ms. Duffey, a seventh grade science teacher, argued that students' digital play was not going to help them get a working class job: "These kids aren't naturally gifted at technology, those skills playing video games don't translate to school. So they have fast phones? So what? The kids we teach, if we are being realistic, they need skills for hands on jobs, like how to fix a new-wave car. If they learn technology it's for that purpose." At Chávez, teachers constructed their lessons in ways that impart technology skills they believed were valuable for working class jobs. But teachers did not imagine working class jobs to be focused on material production (Bowles and Gintis 1976). Ms. Gellar, a sixth grade math teacher, elaborated: "I don't know that these kids are going into managerial positions after school, but they need to know a different set of skills than it used to be in factories. They need basic skills in using computers, research, programming, even making websites. That's the future for these kids." Teachers at Chávez said that they are helping their students by teaching them many new literacies, like computer use, website navigation and construction, and even programming, because they believed these skills would prepare them for a twenty-first century factory. Teachers here did not view poor Latino youth as academic threats, as some literature has suggested (Bobo 2001). Students were indeed taught digital skills. But as I illustrate, this perception of their students motivated a disciplinary orientation to students' digital play that rendered their creative pursuits online as irrelevant to schooling.

Teachers at Chávez constructed a division between valued digital skills taught in class and the less useful digital styles young people bring to school. For example, Mr. Weber, an eighth grade history teacher, agreed that his students were "digital natives" in the sense that they used technologies for fun. "They're all, especially the boys, really great at video games," he said. "But if they are going to succeed in high school and at a job they have to be comfortable with keyboarding. They have to be able to do research, and turn in papers, and they don't know how to do that. It's basic skills." In teachers' view, basic skills constituted types of technology use that were school sanctioned. They did not see video gameplay as a potentially valuable pursuit. Other faculty similarly remarked that if students were tech savvy it is only for texting or using social media, not for academics like website navigation or research. Although the earlier analysis of students' digital play revealed that Chávez students did in fact develop digital skills from 
their play online with friends, teachers curtailed students' digital forms from becoming cultural capital for learning.

Teachers' beliefs about the separation between students' digital youth cultural forms and valued "basic skills" with digital technology filtered into daily classroom instruction. For example, I attended a multi-week series of classes about the value of education taught by Ms. Embry, a seventh grade language arts teacher. By the end of two weeks, students were to create a series of written documents on their iPads that explained their views of the value of education using research citations from the Internet. In each class students worked independently on their iPads at their desks and Ms. Embry walked around the classroom, hands behind her back, and peered onto students' screens. "I know you guys love to type like how you text, using little emoticons and spelling 'you' with the letter 'u'," she said in one class. "That's fine for your friends but that's not what will get you a good grade here." Rather than integrate features from students' own peer cultures, teachers routinely construed these digital forms as irrelevant to learning, instead emphasizing other skills.

In another example, Ms. Bryant was teaching a class on computer programming using software called Scratch. Students were permitted to work independently on their computers, using Scratch to complete challenges that teach the basics of logic to animate a cat on the screen. As part of its design, students could remix different types of audio or image files of their choice into a computer program. "You are free to use whatever media you want to complete the challenge," Ms. Bryant instructed. "But remember, at the end of the day I don't care how pretty your Spongebob looks. You only get full points if you solve the problem." Although some assignments at Chávez provided semi-structured opportunities for students to meld their own interests, like digital media from the Spongebob television show, teachers disciplined play by treating those interests as ultimately irrelevant to schooling. Chávez students were thus taught digital skills but, unlike Heathcliff students, were not permitted to develop the creative potential of those skills.

In interviews, students explained that teachers did not think social media, gaming, and their other digital interests were helpful at school. But they also expressed a lack of engagement in the "basic skills" they are taught with digital technology. For example, Anthony (13 years old, Latino) said that "teachers are worried kids will goof around if we used some of the more fun apps at school. They say it's good to communicate with others using social media but it's not for work." As a consequence of teachers' separation of digital youth cultural participation and school-sanctioned activities, students not only saw their digital styles as irrelevant to school but they also created a division between their interest-driven activities and schooling. "Social media is fun but school isn't open to it because people take advantage of it and mess around with it," said Juliet (13 years old, Latina). "Messing around isn't productive." Students at Chávez came to think of the fun types of messing around on digital platforms as separate from work. If Ito et al. (2010) are right that "messing around" with digital technology is a key part of developing affinity for creative production, then Chávez students missed on that opportunity. Rather, Chávez imposed on students a division between work and play that functioned to relegate their own agentic impulses to time outside of school. This separation aids social reproduction by denying the potential of students' peer culture-driven digital skills to be 
used as cultural capital for achievement in favor of their less engaged pursuit of institutionally acceptable "basic skills" for the digital era.

Teachers at Chávez disciplined play by treating kids' digital skills as irrelevant to learning. But teachers link the source of this disciplinary orientation to a durable set of understandings specific to their school that informed perceptions of students' needs. Mr. Hertzberg, an information technology administrator at Chávez, pointed to the school's culture as important not only for technology but for general practices with kids. "It's out of control of any one person," he said. "Principals and teachers come and go, but there's an understanding here that you have high expectations of these kids. We've been like that for years and years. It's like a family here." Specifically, faculty pointed to the history of Chávez as the reason for their family-like atmosphere. Ms. Fillion, a sixth grade math teacher at the school, explained: "We used to be an elementary school just under ten years ago. The district was getting too big and couldn't accommodate the many, many immigrant families that moved here. So they talked to Mr. Erickson, who was the principal of the elementary school where he and many of us worked, and convinced him to be the head of this middle school. A bunch of us left that school to join him. Sure, the kids we teach are older, but it feels the same. We never had to leave our family." Just under half of the faculty at Chávez moved with Mr. Erickson from an elementary school in the district to found this middle school. When asked about the collaborative workplace, they said it came from the supportive dynamic that was expected back in the day when it was an elementary school. Mr. Chase, a seventh grade science teacher at the school, reflected that Chávez was different from other middle schools where he had taught. "At most junior high schools the teachers have to act like the police almost, be very attentive to discipline," he explained. "But a lot of teachers here used to work with little kids. You wouldn't expect former elementary school teachers to act like cops, and we're probably better off that way." The history of Chávez's founding shaped the family-like dynamic among faculty, which in turn provided a benevolent frame to the race- and class-inflected assumptions of their students.

Teachers' shared perceptions were linked to assumptions about what their student population needed to get ahead. For example, I observed a faculty meeting where teachers and administrators discussed and assembled a plan for digital pedagogy at the school. Mr. Erickson, the principal, opened the meeting by saying they needed to assemble a "vision" for technology use at school. "We can't think of technology as an elective," said Ms. Gellar, a sixth grade math teacher. "It needs to be every day. They need twenty-first century skills to get a job some day." The group nodded in agreement. "And we all know these kids can text and do Instagram," added Ms. Woodside. "But if we want to help them we need to teach them basic skills they'd need to survive high school and hopefully get a job some day." Teachers and administrators at Chávez maintained high expectations of their students for digital pedagogy and otherwise, likely as a consequence of the caring-like atmosphere carried over from its days many years ago as an elementary school. But teachers linked this school culture with stereotypes described earlier about their students heading to, at best, working class jobs. Their disciplinary orientation to play thus minimized the skills these children bring to school to instead focus on teaching basic skills with digital technology.

\section{DISCUSSION}


Digital divides, both at home and at school, are shrinking, and so-called 'digital youth' experience youth culture as digitally mediated. These generational similarities in digital skills among youth could create opportunities, particularly for minority and working class students, to translate their digital skills into cultural capital at school. This presents an opportunity for cultural mobility among disadvantaged youth by leveling the playing field somewhat in terms of access to valued cultural resources (DiMaggio 1982; DiMaggio and Mohr 1985). Teachers, especially at schools serving less privileged students, are positioned to integrate the digital play young people bring to school as a meaningful part of the learning experience. As the literature on technology and education suggests, doing so may mitigate existing inequalities.

Yet the social dynamics within these three technology-rich middle schools are better explained by theories of social reproduction. Although students varied considerably by social class and race at each school, students did indeed share similar experiences as digital youth and brought with them to school valuable skills with digital technology, such as online communication and digital production. But students entered schools with different disciplinary approaches their online play, or the digital skills that come from students' youth cultures.

I find that teachers' shared beliefs about students informed their disciplinary orientations to students' digital play that varied by school, and these orientations determined whether the digital skills students bring to school were transformed into valuable cultural capital for achievement (see Table 3). These assumptions were rooted in both class- and race-based stereotypes that emerged from the recent history of the school and were cultivated and shared by teachers and informed how they saw the value of students' digital skills. Teachers were thus institutional gatekeepers whose perceptions of students shaped whether very similar cultural resources are converted into cultural capital.

\section{Table 3: Disciplinary Orientations to Digital Play and Achievement}

\begin{tabular}{lll} 
School & Teacher Orientation & Instructional Practice \\
\hline $\begin{array}{l}\text { Heathcliff Academy } \\
\text { (Wealthy, White) }\end{array}$ & $\begin{array}{l}\text { Play is essential to } \\
\text { school }\end{array}$ & $\begin{array}{l}\text { Students' digital forms translated } \\
\text { into cultural capital for } \\
\text { achievement }\end{array}$ \\
$\begin{array}{l}\text { Sheldon Junior High } \\
\text { (Middle-class, Asian) }\end{array}$ & $\begin{array}{l}\text { Play is threatening to } \\
\text { school }\end{array}$ & $\begin{array}{l}\text { Students' digital forms heavily } \\
\text { policed and regulated, denied } \\
\text { cultural capital }\end{array}$ \\
$\begin{array}{l}\text { César Chávez Middle } \\
\text { (Working class, Latino) }\end{array}$ & $\begin{array}{l}\text { Play is irrelevant to } \\
\text { school }\end{array}$ & $\begin{array}{l}\text { Students' digital forms positioned } \\
\text { as useless, denied cultural capital }\end{array}$ \\
\hline
\end{tabular}

While Chávez and Sheldon teachers' disciplinary orientations to digital play inhibited its capacity to foster learning, Heathcliff teachers actively promoted an overlap between digital play and work as an agenda for learning. Teachers' assumptions about 
students' privileged position, combined with expectations that youth bring generationspecific digital skills, fueled instructional practices that transformed students' digital skills into valued cultural capital for achievement. Teachers actively used a metaphor of bringing students" "garages" to school to suggest that students should, as part of a learning experience, tinker and mess around with digital technology as a process for learning. So while Chávez and Heathcliff both taught digital skills, only Heathcliff students reported an overlap between digital play and schooling that led them to pursue their interest-driven digital play during class. A key effect was that these privileged students came to see schooling itself as a malleable setting where they could tinker with institutional norms and shape educational ideals. Social reproduction of inequality still occurred, however, because it is only privileged students who were given the pedestal needed to go "under the hood" and ramp schooling up for the digital age - not minority and working class youth. Disciplining play is thus how schools shape students' consciousness by differently cultivating digital laborers, rule-followers, and twenty-first century tinkerers.

One might have expected that Heathcliff teachers have greater technical expertise than those at other schools and have more curricular freedom due to the private character of their institution. Heathcliff parents, too, might put more pressure on teachers to teach digital skills. But teachers were comparably skilled with digital technology at each school. This study also benefited from a period of test reform when faculty at both public schools were unconcerned with standardized exams that may have otherwise affected day-to-day teaching practices. I did find, however, that parents had an influential role. In fact, Heathcliff and Sheldon parents were comparably assertive in their requests that teachers help their children do well in school. The difference was that Sheldon teachers racialized Asian parents as overbearing threats while Heathcliff teachers saw their students' parents as credible sources of influence. Heathcliff teachers were willing to engage and respond to requests from parents, whereas Sheldon teachers were not as forthcoming.

Findings from this study suggest that the racial and class context of schooling inform whether kids' cultural resources can help them get ahead. Part of this problem is that the effects of segregated neighborhoods and its impact on school composition are intimately connected to the social boundaries between the largely White and middle class teacher populations and the non-White, working and middle class students that they serve. Few public schools exist in this particular region that serve working class, White youth, and wealthy, White families increasingly enroll their children in private schools (Suitts 2016). What this shows, too, is that it is simply not enough to teach children skills an expect that those skills will net better educational outcomes. For skills to have meaning as valuable in a given institutional context the must be validated by the context in which they are deployed. They must be recognized by institutional authorities (in this case by teachers) and validated. This is a key process for the development of cultural capital. Further, digital technologies are not a "magic bullet" to addressing inequalities. The histories of each of the schools in this study, which include how members of the school ecology experience neighborhood shifts, informed teachers' disciplinary practices with children that have the effect of reproducing the status quo.

The cultural stereotypes teachers drew upon during instruction were informed by the school context and in ways that did not always map on to the existing literature on 
race, class, and teacher perceptions. For example, although Asian students at Heathcliff were seen as model minorities due to the climate of elite servitude, Asian students at Sheldon were perceived as threatening hackers due to teachers' negative reception of the recent history of immigration in the neighborhood (Lee and Zhou 2015). Latino students at Chávez were perceived as benevolent immigrants due to the family-like dynamics at the school, whereas the minority of Latino students at Sheldon were more in line with the gang member imagery (Rios 2011; Valenzuela 1999). White invisibility also played a critical role in the success of White students no matter the school context. Unlike minority students, White students' performances were seen as individual rather than a collective representation of their racial group (McIntyre 1997). This shielded White students from teachers' negativity at Sheldon which was directed almost exclusively towards their majority Asian student body and smaller Latino minority.

An important implication of this work is that teachers' different disciplinary orientations to kids' play may guide them into different paths for college applications and admission. For example, Heathcliff students are more able to report the innovative digital projects they created and shared at school, whereas students who attended Sheldon or Chávez will not because teachers did not give them this opportunity. In other words, these schools differently enable a means by which youth can demonstrate their academic potential to college admissions offers (Stevens 2009).

Although this study focuses on kids' cultural resources from play with friends online, we may soon bear witness digitally-inflected cultural stratification through childrearing. As cohorts of digital youth age and eventually become parents themselves, they will begin teaching new generations sets of digital habits and skills that will be differently linked to expectations by the dominant class. But the form that these distinctions take may be different than we have witnessed in the existing literature, which typically focus on knowledge acquisition of high culture or cultural omniverousness (DiMaggio 1982; Khan 2011; Lizardo 2006). Student interviews suggest that kids are developing different habits with publicity online, including whether and what they are willing to share about themselves online. Kids' digital footprints may eventually be differently cultivated by parents and in ways that may or may not meet institutional expectations, such as by teachers or even college admissions.

This study certainly has a number of limitations that offer considerable grounds for future work. Due to both the relatively monolithic demographic composition of each school and my focused analytic gaze on school-level messaging, there may be greater within-school patterns of stratification at schools with more diverse student populations. It may also be worthwhile to examine other types of schools, including selective public schools and charter schools, to examine if their institutional status operates similarly to the schools in this project. In addition, although minority teachers and students in this study shared similar reports to their majority colleagues and classmates at the same school, it also may be that teachers who occupy different class and racial-ethnic statuses have different perspectives than the White, middle-class teachers in this study.

While scholars have long assumed that students encounter stratified entry points upon school enrollment, there is little examination of how schools may differently foster digital skills. Prior theorizing on social reproduction in schools suggests that parents transmit to children different and unequal cultural resources across class and race that lead to inequalities in achievement (Bourdieu 1977a; Bourdieu 1986; Bourdieu and 
Passeron 1990; DiMaggio 1982; Lareau 2000; 2003). This study builds on this literature by illustrating that schools unevenly legitimate kids' similar cultural displays and in ways that matter for achievement (Bowles and Gintis 1976; Lareau and Horvat 1999; Roscigno and Ainsworth-Darnell 1999). Schools reify the status order in the digital age by disciplining play. Teachers' shared class- and race-based perceptions of their students drive their disciplinary approach to play in day-to-day classroom practice. They transform digital expressions of youth at schools with mostly privileged youth into cultural capital for learning while dismissing the digital play of youth at schools with mostly minority and working class students as threatening or irrelevant to education.

\section{REFERENCES}

Anyon, Jean. 1980. "Social Class and the Hidden Curriculum of Work." Journal of Education 162(1): 3-42.

Anyon, Jean. 1981. "Social Class and School Knowledge." Curriculum Inquiry 11(1): 342.

Bobo, Lawrence. 2001. "Racial Attitudes at the Close of the Twentieth Century." America Becoming: Racial Trends and their Consequences. 1: 264-301.

Bourdieu, Pierre. 1977a. "Cultural Reproduction and Social Reproduction." In Power and Ideology in Education, edited by Jerome Karabel and A. H. Halsey. New York: Oxford University Press.

Bourdieu, Pierre. 1977b. Outline of a Theory of Practice. New York: Cambridge Univ. Press.

Bourdieu, Pierre. 1986. "The Forms of Capital.” In Handbook of Theory and Research for the Sociology of Education, edited by J. G. Richardson. New York: Greenwood Press.

Bourdieu, Pierre, and Jean-Claude Passeron. 1990. Reproduction in Education, Society and Culture. London: Sage.

Bowles, Samuel, and Herbert Gintis. 1976. Schooling in Capitalist America: Educational Reform and the Contradictions of Economic Life. New York: Basic Books.

Calarco, Jessica McCrory. 2011. "'I Need Help!' Social Class and Children's HelpSeeking in Elementary School." American Sociological Review 76(6): 862-882.

Calarco, Jessica McCrory. 2014a. "Coached for the Classroom: Parents' Cultural Transmission and Children's Reproduction of Educational Inequalities." American Sociological Review 79(5): 1015-1037.

Calarco, Jessica McCrory. 2014b. "The Inconsistent Curriculum: Cultural Tool Kits and Student Interpretations of Ambiguous Expectations." Social Psychology Quarterly 77(2): 185-209.

Carter, Prudence L. 2005. Keepin' it Real: School Success Beyond Black and White. Oxford: Oxford University Press.

Carter, Prudence L. 2012. Stubborn Roots: Race, Culture, and Inequality. Oxford: Oxford Univeristy Press.

Castells, Manuel. 1998. The Information Age: Economy, Society, and Culture. Volume III - End of Millenium. Oxford: Blackwell.

Collins, Allan, and Richard Halverson. 2009. Rethinking Education in the Age of Technology:The Digital Revolution and Schooling in America. New York: 
Teachers College Press.

Dede, C., Korte, S., Nelson, R., Valdez, G., \& Ward, D. 2005. "Transforming Learning for the 21st Century: An Economic Imperative." Learning Point Associates.

DiMaggio, Paul. 1982."Cultural Capital and School Success: The Impact of Status Culture Participation on the Grades of U.S. High School Students." American Sociological Review 47:189-210.

DiMaggio, Paul and John Mohr. 1985. "Cultural Capital, Educational Attainment, and Marital Selection." American Journal of Sociology 90:1231-61.

Drexler, W., Baralt, A., \& Dawson, K. 2008. "The teach web 2.0 consortium: a tool to promote educational social networking and web 2.0 use among educators." Educational Media International 45(4): 271-283.

Emerson, Robert M., Rachel L. Fretz, and Linda L. Shaw. 1995. Writing Ethnographic Fieldnotes. Chicago: University of Chicago Press.

Ertmer, Peggy A., Anne T. Ottenbreit-Leftwich, Olgun Sadik, Emine Sendurur, and Polat Sendurur. 2012. "Teacher Beliefs and Technology Integration Practices: A Critical Relationship." Computers \& Education 59: 423-435.

Farkas, George. 1996. Human Capital or Cultural Capital? Ethnicity and Poverty

Groups in an Urban School District. New York: Aldine de Gruyter.

Farkas, George, Robert Grober, Daniel Sheehan, and Yuan Shaun. 1990. "Cultural Resources and School Success: Gender, Ethnicity, and Poverty Groups within an Urban District." American Sociological Review 55:127-142.

Feistritzer, C. Emily. 2011. Profile of Teachers in the U.S. 2011. National Center for Education Information. Washington: D.C.

Foucault, Michel. 1975. Discipline and Punish: The Birth of the Prison. New York: Vintage.

Friere, Paolo. 1996. Pedagogy of the Oppressed. New York: Penguin.

Gamoran, Adam, and Richard D. Mare. 1989. "Secondary School Tracking and Educational Inequality: Compensation, Reinforcement, or Neutrality?" American Journal of Sociology 94(5): 1146- 1183.

Hargittai, Ezster. 2003. "Serving Citizens' Needs: Minimizing Hurdles to Accessing Government Information Online." IT \& Society 1(3): 27-41.

Hargittai, Ezster, and Gina Walejko. 2008. "The Participation Divide: Content Creation and Sharing in the Digital Age." Information, Communication \& Society 11(2): 239-256.

Horvat, Erin McNamara, and Anthony Linsing Antonio. 1999. "Hey Those Shoes Are out of Uniform': African American Girls in an Elite High School and the Importance of Habitus." Anthropology \& Education Quarterly 30(3): 317-342.

Irizarry, Yasmiyn. 2015. "Utilizing Multidimensional Measures of Race in Education Research: The Case of Teacher Perceptions." Sociology of Race \& Ethnicity 1(4): 564-583.

Ito, Mizuko, Sonja Baumer, Matteo Bittanti, danah boyd, Rachel Cody, Becky HerrStephenson, Heather A. Horst, Patricia G. Lange, Dilan Mahendran, Katynka Z. Martínez, C.J. Pascoe, Dan Perkel, Laura Robinson, Christo Sims, and Lisa Tripp. 2009. 2009. Hanging Out, Messing Around, and Geeking Out: Kids Living and Learning with New Media. Cambridge, MA: MIT Press. 
Ito, Mizuko, Kris Gutiérrez, Sonia Livingstone, Bill Penuel, Jean Rhodes, Katie Salen, Juliet Schor, Julian Sefton-Green, and S. Craig Watkins. 2013. Connected Learning: An Agenda for Research and Design. Irvine, CA: Digital Media and Learning Research Hub.

International Society for Technology in Education (ITSE). 2007. "ITSE Standards: Students." Arlington, Virginia.

Kinney, David. 1993. "From Nerds to Normals: The Recovery of Identity among Adolescents from Middle School to High School." Sociology of Education 66(1): 21-40.

Khan, Shamus. 2011. Privilege: The Making of an Adolescent Elite at St. Paul's School. Princeton: Princeton University Press.

Kruse, Sharon D. and Karen Seashore Louis. 2009. Building Strong School Cultures: A Guide to Leading Change. Thousand Oaks, CA: Corwin Press.

Lareau, Annette. 2000. Home Advantage: Social Class and Parental Intervention in Elementary Education. New York: Rowman and Littlefield Publishers.

Lareau, Annette. 2003. Unequal Childhoods: Class, Race, and Family Life. Berkeley: University of California Press.

Lareau, Annette, and Erin McNamara Horvat. 1999. "Moments of Social Inclusion and Exclusion: Race, Class and Cultural Capital in Family School Relationships."Sociology of Education 72(1): 37-53.

Lareau, Annette, and Elliot B. Weininger. 2003. "Cultural Capital in Educational Research: A Critical Assessment." 2003. Theory and Society 32: 567-606.

Lee, Jennifer and Min Zhou. 2015. The Asian American Achievement Paradox. New York: Russell Sage Foundation.

Lenhart, Amanda. 2015a. "Teens, Social Media \& Technology Overview 2013: Smartphones Facilitate Shifts in Communication Landscape for Teens." Pew Research Center. Washington, D.C.

Lenhard, Amanda. 2015b. "A Majority of American Teens Report Access to a Computer, Game Console, Smartphone and a Tablet." Pew Research Center. Washington, D.C.

Lenhart, Amanda, Rich Ling, Scott Campbell, and Kristen Purcell. 2010. "Teens and Mobile Phones." Pew Internet \& American Life Project. Washington, D.C.

Lewis, Amanda. 2003a. "Everyday Race-Making." American Behavioral Scientist 47(3): 283-305.

Lewis, Amanda. 2003b. Race in the Schoolyard: Negotiating the Color Line in Classrooms and Communities. New Brunswick: Rutgers University Press.

Lizardo, Omar. 2006. "How Cultural Tastes Shape Personal Networks." American Sociological Review 71: 778.

Madden, Mary, Amanda Lenhart, Maeve Duggan, Sandra Cortesi, and Urs Gasser. 2013. "Teens and Technology." Pew Research Center's Internet \& American Life Project. Washington, D.C.

McDonough, Patricia M. 1997. Choosing Colleges: How Social Class and Schools Structure Opportunity. Albany: State University of New York Press.

McIntyre, Alice. 1997. Making Meaning of Whiteness: Exploring Racial Identity with White Teachers. Albany: State University of New York Press.

Moller, Stephanie, Elizabeth Stearns, Roslyn Arlin Mickelson, Martha Cecilia Bottia, and 
Neena Banerjee. 2014. Social Forces 92(4): 1513-1544.

NTIA (National Telecommunications and Information Administration). 2000. Falling

Through the Net: Toward Digital Inclusion. Washington, DC: US Dep.

Commerce.

Orfield, Gary, and Nora Gordon. 2001. Schools More Separate: Consequences of a Decade of Resegregation. Cambridge: The Civil Rights Project, Harvard Univeristy.

Overbay, Amy, Ashley S. Patterson, Ellen S. Vasu, and Lisa L. Grable. 2919.

"Constructivism and Technology Use: Findings from the Impacting Leadership Project." Educational Media International 47(2): 103-120.

Peppler, Kylie A., and Yasmin B. Kafai. 2007. "From SuperGoo to Scratch: Exploring Creative Digital Media Production in Informal Learning." Learning, Media and Technology 32(2): 149-166.

Rainie, Lee. 2011. "Asian-Americans and Technology." Pew Research Center. Washington, D.C.

Rios, Victor M. 2011. Punished: Policing the Lives of Black and Latino Boys. New York: New York University Press.

Roscigno, Vincent J., and James W. Ainsworth-Darnell. 1999. "Race, Cultural Capital, and Educational Resources: Persistent Inequalities and Achievement Returns." Sociology of Education 72(3): 158-178.

Schoenfeld, Alan H. 2000. "Purposes and Methods of Research in Mathematics Education." Notices of the AMS, 47(6), 641-649.

Schrum, Lynne R., and Barbara B. Levin. 2009. Leading 21st Century Schools: Harnessing Technology for Engagement and Achievement. Thousand Oaks, CA: Corwin.

Sefton-Green, Julian, and Elisabeth Soep. 2007. "Creative Media Cultures: Making and Learning Beyond the Scope of School." In International Handbook of Research in Arts Education, edited by L. Bresler. Netherlands: Springer.

Stark, Joan S. 2000. "Planning introductory college courses: Content, context and form." Instructional Science 28: 413-438.

Stevens, Mitchell L. 2009. Creating a Class: College Admissions and the Education of Elites. Cambridge: Harvard University Press.

Suitts, Steve. 2016. "Race and Ethnicity in a New Era of Public Funding of Private Schools: Private School Enrollment in the South and the Nation." Atlanta: Southern Education Foundation, Inc.

Swidler, Ann. 1986. "Culture in Action." American Sociological Review 51(2): 273-86.

Tufecki, Zeynep. 2008a. "Can You See Me Now? Audience and Disclosure Regulation in Online Social Network Sites.” Bulletin of Science, Technology \& Society 28(1): 20-36.

Tufecki, Zeynep. 2008b. "Grooming, Gossip, Facebook and MySpace.” Information, Communication \& Society 11(4): 544-564.

U. S. Department of Education, Office of Educational Technology. (2010). Transforming American Education: Learning Powered by Technology. National Educational Technology Plan 2010.

Valenzuela, Angela. 1999. Subtractive Schooling: U.S. Mexican Youth and the Politics of Caring. Albany, N.Y; State University of New York Press. 
Van Duerson, Alexander, and Jan Van Dijk. 2010. "Internet skills and the digital divide." New Media \& Society 13(6): 893-911.

Warschauer, Mark. 2011. Learning in the Cloud. New York: Teachers College Press.

Wellman, Barry, Anabel Quan Haase, James Witte, and Keith Hampton. 2001. "Does the internet increase, decrease, or supplement social capital?" American Behavioral Scientist 45(3): 436-455.

Wheeler, Steve. 2009. Connected Minds, Emerging Cultures: Cybercultures in Online Learning. Charlotte: Information Age.

Wheeler, Steve, Peter Yeomans, and Dawn Wheeler. 2008. "The Good, the Bad and the Wiki: Evaluating Student-Generated Content for Collaborative Learning." British Journal of Educational Technology 39(6): 987-995.

Williams, Christine C. 1993. Doing 'Women's Work': Men in Non-traditional Occupations. Newbury Park: Sage.

Zickhur, Kathryn. 2010. “Generations 2010.” Pew Research Center's Internet \& American Life Project. 
Appendix 1: Teacher Sample Characteristics

\begin{tabular}{lccc}
\hline & Heathcliff Academy & Sheldon Junior High & César Chávez Middle \\
\cline { 2 - 4 } Years Taught & & & \\
Mean & 10.89 & 10.54 & 10.87 \\
SD & 5.40 & 7.58 & 6.73 \\
Technology Training & & & \\
Mean & 0.28 & 0.23 & 0.22 \\
SD & 0.46 & 0.43 & 0.42 \\
& & & \\
Graduate School & & & 0.31 \\
Mean & 0.22 & 0.35 & 0.47 \\
SD & 0.43 & 0.49 & \\
\hline
\end{tabular}

Note: Years Taught is a continuous variable, and Technology Training and Graduate School are dichotomous variables. Teachers responded with "no" (coded as 0) or "yes" (coded as 1) to these questions during interviews. 